\title{
Combined high expression of CD47 and CD68 is a novel prognostic factor for breast cancer patients
}

\author{
Jingping Yuan ${ }^{1}$, Huihua He ${ }^{1}$, Chuang Chen², Juan Wu' ${ }^{1}$ Jie Rao and Honglin Yan ${ }^{1 *}$ (C)
}

\begin{abstract}
Background: Avoiding the phagocytosis by tumor-associated macrophages (TAMs) is necessary for the growth and metastasis of solid tumors. CD47 binds to the receptor signal-regulatory protein-a (SIRP-a) on the macrophages to avoid normal phagocytosis. In this study, we evaluated the expression and prognostic significance of CD47 and CD68labeled TAMs in breast cancer solid tumors.

Methods: Two hundred seventeen cases of breast cancer tissues and 40 cases of benign breast lesions were collected for immunohistochemical staining of CD47 and CD68.

Results: Both of the CD47 and CD68 expression were significantly higher in breast cancer tissues $(P<0.001)$, and associated with multiple clinicopathological parameters in breast cancer $(P<0.05)$. However, CD47 or CD68 expression alone was not an independent predictor of poor DFS in multivariate survival analysis $(P>0.05)$. Interestingly, combined high expression of CD47 and CD68 (CD47 ${ }^{\text {high }} C D 68^{\text {high }}$ ) not only had a significant association with advanced TNM stage, histological grade, LNM, ER status, PR status and recurrence $(P<0.05)$, but also displayed a poorer 5-DFS $(P=0.011)$. Strikingly, $C D 47^{\text {high }} \mathrm{CD} 68^{\text {high }}$ served as a novel independent prognostic factor for poor DFS compared to the expression of CD47 or CD68 alone $(P=0.045)$. Furthermore, our study also showed for the first time that the prognostic significance of $C D 47^{\text {high }} \mathrm{CD} 68^{\text {high }}$ not only in breast cancer in general, but also in hormone receptor-negative breast cancer in particular.
\end{abstract}

Conclusions: Combined detection of CD47 and CD68 may provide guidance for the prognosis of breast cancer, especially hormone receptor-negative breast cancer.

Keywords: Breast cancer, Hormone receptor-negative breast cancer, CD47, CD68

\section{Background}

Breast cancer is one of the three most common cancers in the world and is also the most common cancer among Chinese women [1, 2]. China accounts for $12.2 \%$ of all newly diagnosed breast cancer cases and $9.6 \%$ of all breast cancer deaths worldwide [2]. It is common knowledge that cancer cells have a strong ability to proliferate indefinitely, escape immunity, local invasion and distant

\footnotetext{
*Correspondence: honglin1229@163.com

${ }^{1}$ Department of Pathology, Renmin Hospital of Wuhan University, No.99, Zhangzhidong Road, Wuchang District, Wuhan 430060, Hubei, People's Republic of China

Full list of author information is available at the end of the article
}

metastasis, but the mechanism has not been fully elucidated. Current studies have shown that the development of breast cancer is a complex event involving multiple factors, stages and links. In this process, cancer cells interact with multiple components of the tumor microenvironment to co-evolution [3, 4]. Tumor microenvironment is a complex and comprehensive system, which includes vascular endothelial cells, immune cells, macrophages, fibroblasts, basement membrane, collagen IV and other non-cellular components in addition to tumor cells [3].

Macrophages are the main immune cells infiltrating into the microenvironment of tumors. According to the signal stimulation of the microenvironment, they can 
polarized into two distinct phenotypes, the classically activated (M1) or the alternative activated (M2) macrophages. Traditionally, M1 macrophages are associated with less tumor invasiveness, while M2 macrophages induce tumor growth and lead to poor prognosis [5]. Tumor-associated macrophages (TAMs), which closely resemble the M2-polarized, are generally characterized by the expression of cell surface marker CD68 [6, 7]. They are important prognostic factors of tumors and have been demonstrated to be correlated with invasion and migration of various tumors [8-10]. Over the past few years, studies on the role of TAMs in the progression of breast cancer have confirmed that TAMs in breast cancer can enhance the invasion of tumor cells and lead to poor prognosis of patients by remodeling extracellular matrix (ECM), inducing angiogenesis, inhibiting the anti-tumor function of cytotoxic $\mathrm{T}$ cells, modelling breast cancer cells to escape the host immune system, and recruiting immunosuppressed leukocytes into tumor microenvironment [7].

Recent studies have shown that the reason why macrophages can be counteracted to help the growth of cancer cells is related to the molecular changes on the surface of macrophages and cancer cells [11-13]. Macrophagemediated programmed cell removal (PrCR) is based on Calreticulin (CRT), an "eat-me signal" on the surface of cancer cells, which interacts with LDL-receptor-related protein (LRP) on the macrophages and recruits macrophages to phagocytize cancer cells [11]. It is an important mechanism for clearing disease and damaged cells before programmed cell death. However, in the course of cancer development, some cancer cells also express another protein, CD47, a kind of "don't eat me" signal [12]. This protein binds to the receptor signal-regulatory protein- $\alpha$ (SIRP- $\alpha$ ) on the phagocytes to inhibit normal phagocytosis [12]. Therefore, the induction of PrCR by "eat-me" signal on tumor cells is counteracted by "don't eat me" signal, thus avoiding macrophage phagocytosis.

CD47, also known as integrin associated protein (IAP), is a ubiquitous membrane protein belonging to the immunoglobulin superfamily. Compared with normal cells, CD47 is highly expressed in many cancer cells or tissues, such as non-Hodgkin lymphoma cells [14], acute lymphoblastic leukemia cells [15], bladder tumor-initiating cells [16], breast cancer cells [17], myeloma cells [18], hepatocellular carcinoma [19], etc. Recent studies have found that tumor cells evade the phagocytosis and killing effect of macrophages by overexpressing CD47 and induce immune escape of tumor cells $[12,20,21]$. Several studies have shown that the overall survival rate of patients with high expression of CD47 is significantly poorer than that of patients with low expression of CD47 [22-24]. Accordingly, CD47 is considered as a biomarker of several cancer, and its high expression can be used a poor prognostic factor. In breast cancer, only a few studies focused on CD47 at the cytological level, such as breast cancer cell lines, breast cancer stem cells, peripheral blood cells and circulating tumor cells of breast cancer patients [17, 22, 25-27], the expression of CD47 in breast cancer solid tumors have been rarely reported [23].

In this study, we evaluated the expression of CD47 in 217 solid breast cancer tissues and 40 benign breast lesions. Additionally, we measured the expression of TAMs by CD68 immunohistochemical staining. Our study showed for the first time that combined high expression of CD47 and CD68 represented an even better independent predictor for poor prognosis compared to the expression of CD47 or CD68 alone, and could be a novel prognostic factor for breast cancer patients. Moreover, the prognostic significance of combined high expression of CD47 and CD68 not only in breast cancer in general, but also in hormone receptor-negative breast cancer in particular. Therefore, our study provides a new therapeutic target for breast cancer, especially hormone receptor-negative breast cancer.

\section{Materials and methods \\ Tissue samples}

The cohort consisted of 217 formalin-fixed paraffin embedded (FFPE) tissue samples of primary invasive breast cancer receiving no treatment prior to surgery. Forty cases of benign breast lesions were collected as controls. All tissue samples were randomly selected from the medical records of the Department of Pathology, Renmin Hospital of Wuhan University between August 2009 and December 2010. Corresponding clinicopathologic data were extracted from medical records and pathology reports. Ages at diagnosis ranged from 29 to 78 years old with an average age of 48.1 years. The main clinicopathological parameters in the study group included age, menopausal status, tumor node metastasis (TNM) stage, histological grade, lymph node metastasis (LNM), estrogen receptor (ER), progesterone receptor (PR), human epidermal growth factor receptor 2 (HER2) and recurrence, as shown in Table 1. Patients were all followed up for 5 years. The follow-up data was defined as the time between the date of the first diagnosis and the date of death or last follow-up time. Written informed consent was obtained from the patients before surgery, and specimens were allowed to be used for scientific research purposes. The study was approved by the Ethics Committee of Renmin Hosptial of Wuhan University. 
Table 1 Correlation between CD47, CD68 or CD47-CD68 expression and clinicopathological parameters in breast cancer

\begin{tabular}{|c|c|c|c|c|c|c|c|c|c|c|}
\hline \multirow{2}{*}{$\begin{array}{l}\text { Clinicopathological } \\
\text { parameters }\end{array}$} & \multirow[t]{2}{*}{$\mathbf{n}$} & \multicolumn{3}{|l|}{ CD47 } & \multicolumn{3}{|l|}{ CD68 } & \multicolumn{3}{|l|}{ CD47-CD68 } \\
\hline & & $\begin{array}{l}\text { High } \\
\text { expression } \\
\text { (\%) }\end{array}$ & $x^{2}$ & $P$ & $\begin{array}{l}\text { High } \\
\text { expression } \\
\text { (\%) }\end{array}$ & $x^{2}$ & $P$ & $\begin{array}{l}\text { High } \\
\text { expression } \\
\text { (\%) }\end{array}$ & $x^{2}$ & $P$ \\
\hline \multicolumn{11}{|l|}{ Age (years) } \\
\hline$<50$ & 134 & 64.2 & 0.017 & 0.895 & 67.9 & 3.452 & 0.063 & 48.5 & 0.223 & 0.637 \\
\hline$>50$ & 83 & 65.1 & & & 79.5 & & & 51.8 & & \\
\hline \multicolumn{11}{|l|}{ Menopause } \\
\hline Before & 122 & 63.9 & 0.041 & 0.839 & 67.2 & 3.676 & 0.055 & 45.9 & 1.668 & 0.197 \\
\hline After & 95 & 65.3 & & & 78.9 & & & 54.7 & & \\
\hline \multicolumn{11}{|l|}{ TNM stage } \\
\hline I & 13 & 23.1 & 11.249 & 0.004 & 53.8 & 10.844 & 0.004 & 7.7 & 16.769 & $<0.001$ \\
\hline$\|$ & 137 & 65.0 & & & 67.2 & & & 46.0 & & \\
\hline III & 67 & 71.6 & & & 86.6 & & & 65.7 & & \\
\hline \multicolumn{11}{|l|}{ Histological grade } \\
\hline G1 & 36 & 44.4 & 10.825 & 0.004 & 69.4 & 10.500 & 0.005 & 47.2 & 11.300 & 0.004 \\
\hline G2 & 126 & 64.3 & & & 62.9 & & & 42.1 & & \\
\hline $\mathrm{G} 3$ & 55 & 78.2 & & & 89.1 & & & 69.1 & & \\
\hline \multicolumn{11}{|c|}{ Lymph node metastasis } \\
\hline No & 96 & 58.3 & 2.875 & 0.090 & 63.5 & 6.678 & 0.010 & 40.6 & 5.759 & 0.016 \\
\hline Yes & 121 & 69.4 & & & 79.3 & & & 57.0 & & \\
\hline \multicolumn{11}{|l|}{ ER status } \\
\hline Negative & 121 & 71.1 & 5.139 & 0.023 & 78.5 & 5.192 & 0.023 & 61.2 & 8.253 & 0.004 \\
\hline Positive & 96 & 56.3 & & & 64.6 & & & 35.4 & & \\
\hline \multicolumn{11}{|l|}{ PR status } \\
\hline Negative & 120 & 73.3 & 9.117 & 0.003 & 79.2 & 6.235 & 0.013 & 55.8 & 3.948 & 0.047 \\
\hline Positive & 97 & 53.6 & & & 63.9 & & & 42.3 & & \\
\hline \multicolumn{11}{|l|}{ HER2 gene } \\
\hline Non-amplification & 163 & 61.3 & 2.869 & 0.090 & 72.4 & 0.001 & 0.981 & 48.5 & 0.445 & 0.505 \\
\hline Amplification & 54 & 74.1 & & & 72.2 & & & 53.7 & & \\
\hline \multicolumn{11}{|l|}{ Recurrence } \\
\hline No & 130 & 31.4 & 3.957 & 0.047 & 61.5 & 7.651 & 0.006 & 40.8 & 10.507 & 0.001 \\
\hline Yes & 87 & 72.4 & & & 79.3 & & & 63.2 & & \\
\hline
\end{tabular}

Significant $P$-values are shown in italic type

\section{Immunohistochemical staining}

Immunohistochemical staining of CD47 and CD68 was performed using a standard Envision complex method. Formalin-fixed, paraffin-embedded tissue samples were cut at $4 \mu \mathrm{m}$, preheated at $60{ }^{\circ} \mathrm{C}$ for $1 \mathrm{~h}$ and then deparaffinized and rehydrated endogenous peroxidase activity was blocked by using $3 \% \mathrm{H}_{2} \mathrm{O}_{2}$. Antigen retrieval was carried out by microwave heating with citrate buffer ( $\mathrm{pH}$ 6.0) for $20 \mathrm{~min}$. After that, sections were incubated with primary antibody (anti-CD47, 1:100, ab213079, Abcam, Cambridge, MA, USA; anti-CD68, 1:100, ab213363, Abcam, Cambridge, MA, USA) for $1 \mathrm{~h}$ at $37{ }^{\circ} \mathrm{C}$, and then incubated with biotinylated secondary antibody using the Dako Cytomation LSAB2 System-HRP (K0672, DakoCytomation, Carpinteria, CA,
USA) for $40 \mathrm{~min}$ at $37^{\circ} \mathrm{C}$. After then, the sections were immersed in 3,3'diaminobenzidine (DAB) at room temperature without light for 2 or $3 \mathrm{~min}$. Finally, samples were slight counterstained with hematoxylin for $2 \mathrm{~min}$. The sections with PBS, replacing the primary antibody, were used as negative controls.

\section{Evaluation of immunohistochemical staining}

Immunohistochemical staining of CD47 and CD68 was evaluated by two experienced independent pathologists (Jingping Yuan and Huihua He). The evaluating pathologists were blinded to clinical data. Unclear cases were discussed until consensus was achieved. CD47 protein was mainly expressed in the cytoplasm or cell membrane of tumor cells. We used CD68 as a marker to evaluate 
TAMs. CD68 protein was predominantly located in cell membranes and cytoplasm of macrophages. Considering the heterogeneity of immunohistochemical staining intensity and distribution, the evaluation of CD47 and CD68 were scored by applying a semi-quantitative immunoreactivity scoring (IRS) system according to the staining intensity and the percentage of positive cells as described by Baccelli et al. [17]. The staining intensity was categorized into four grades as follows, 0 standed for no immunostaining (non-staining), 1 standed for weak (light yellow), 2 standed for moderate (brown yellow), 3 standed for strong (dark brown). The percentage of positive cells was categorized into five grades as follows: 0 standed for none, 1 standed for $1-10 \%, 2$ standed for $11-50 \%, 3$ standed for $51-80 \%$ and 4 standed for $>80 \%$. Three most representative felds of high magnification $(400 \times)$ in each individual case were selected to calculate the final score. Multiplication of the staining intensity and the percentage of positive cells resulted in an IRS ranging from 0 to 12 for each individual case. A case with high expression of protein was scored when scoring between 7 and 12, while a case with low expression of protein was scored when scoring between 0 and 6 .

\section{Statistical analysis}

Chi-square test was used to analyze the association between categorical variables. Spearman's rank correlation analysis was performed to evaluate correlations between variables. The survival curves were disposed by using the Kaplan-Mayer analysis and log-rank test. Prognostic values of variables were estimated by Cox proportional hazard ratio models. Hazard ratios (HRs) and their 95\% confidence intervals (CIs) were calculated for multivariate analyses. SPSS software version 19.0 was used to carry out all the statistical analyses and a $P$-value less than 0.05 was considered as statistically significant.

\section{Results}

\section{Expression and the prognostic value of CD47 in breast} cancer

Two hundred seventeen cases of primary invasive breast cancer and 40 cases of benign breast lesions were collected to examine the expression level of CD47 protein by IHC staining. As shown in Fig. 1a, b, CD47 protein was mainly localized in the cytoplasm or cell membrane of tumor cells in breast cancer tissues, while the immunoreactivity for CD47 in benign breast lesions was negative or weakly positive in the cytoplasm. Of 217 breast cancer tissues, 140 (64.5\%) showed high expression of CD47 protein and 77 (35.5\%) showed low expression. In 40 cases of benign breast lesions, 12 (30.0\%) showed high expression of CD47 protein and $28(70.0 \%)$ showed low expression. The expression of CD47 was significantly higher in breast cancer tissues $\left(\chi^{2}=16.652, P<0.001\right)$ as determined by Chi-square test. In addition, the associations between CD47 expression and clinicopathological parameters were further analyzed. As shown in Table 1, high CD47 expression had a significant association with advanced TNM stage $\left(\chi^{2}=11.249, P=0.004\right)$, histological grade $\left(\chi^{2}=10.825, P=0.004\right)$, ER status $\left(\chi^{2}=5.139\right.$, $P=0.023)$, PR status $\left(X^{2}=9.117, P=0.003\right)$ and recurrence $\left(\chi^{2}=3.957, P=0.047\right)$, indicating that $C D 47$ may be one of the prognostic factors of breast cancer. However, Kaplan-Meier analysis and log-rank test showed that high CD47 expression in breast cancer tissues had a limited association with reduced 5-year disease-free survival (5-DFS) $(P=0.057)$ (Fig. 2a). On the other hand, Cox proportional hazards model analysis also revealed that CD47 was not an independent predictor of poor DFS $(P=0.063$; HR $=1.732,95 \%$ CI $0.970-3.093)$ as by multivariate analysis including the following co-variables of classical prognostic factors: TNM stage, histological grade, LNM, ER status, PR status and HER2 gene (Table 2).

\section{Expression and the prognostic value of CD68 in breast cancer}

CD68 protein was mainly localized in the membrane and cytoplasm of macrophages (Fig. 1c, d). High expression of CD68 protein was found in 157 cases (72.4\%) of breast cancer patients, while in 15 cases $(38.4 \%)$ of benign breast lesions. It suggested that CD68 was significantly increased in breast cancer tissues in comparison to benign breast lesions $\left(\chi^{2}=18.532, P<0.001\right)$. High CD68 expression had a significant association with advanced TNM stage $\left(\chi^{2}=10.844, P=0.004\right)$, histological grade $\left(\chi^{2}=10.500, P=0.005\right), \quad$ LNM $\quad\left(\chi^{2}=6.678, P=0.010\right)$, ER status $\left(\chi^{2}=5.192, P=0.023\right), P R$ status $\left(\chi^{2}=6.235\right.$, $P=0.013)$ and recurrence $\left(\chi^{2}=7.651, P=0.006\right)$. Moreover, the Kaplan-Mayer analysis and log-rank test indicated a strong association of high expression of CD68 with reduced 5-DFS $(P=0.010)$ (Fig. 2b), predicting a poorer survival and lower mortality rate. To further validate the prognostic significance of CD68, Cox proportional hazards model analysis was also performed. As presented in Table 3, CD68 was not an independent predictor of poor DFS $(P=0.212 ; \mathrm{HR}=1.507,95 \% \mathrm{CI}$ $0.791-2.873)$.

\section{Combined high expression of CD47 and CD68 is associated with poor prognosis in breast cancer}

It is reported that CD47 was highly expressed in many cancer cells or tissues, and binded to phagocytes to inhibit normal phagocytosis [12], suggesting that CD47 expression may affect the distribution and expression of macrophages. In accordance with this, we found the frequent presence 

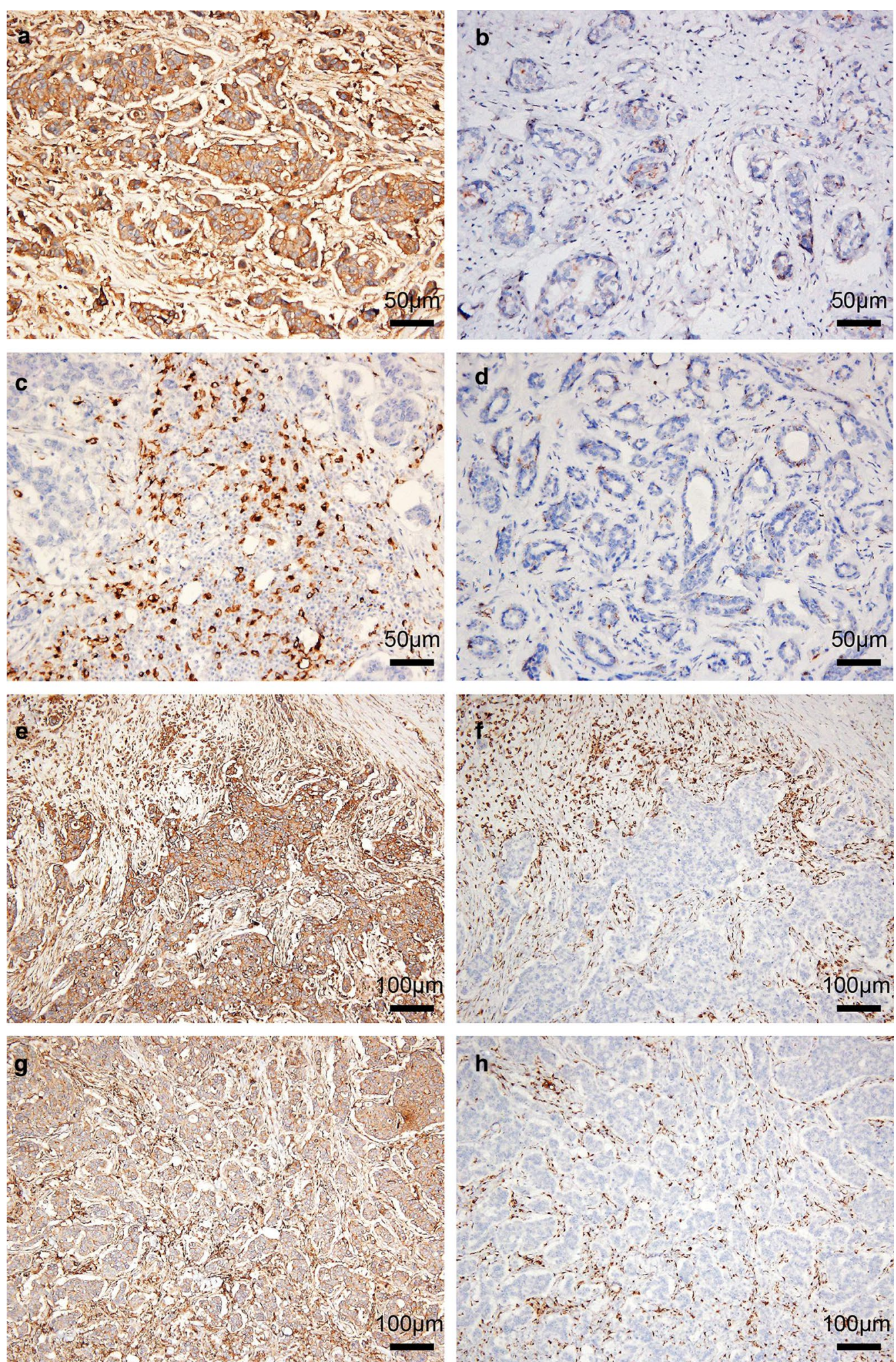

Fig. 1 Immunohistochemical staining for CD47 and CD68 in representative tissue specimens. a The expression of CD47 in breast cancer tissues. b The expression of CD47 in benign breast lesions. c The expression of CD68 in breast cancer tissues. $\mathbf{d}$ The expression of CD68 in benign breast lesions. e, f frequent presence of CD68 (f) around the nest of breast cancer with high expression of CD47 (e). $\mathbf{g}, \mathbf{h}$ Frequent presence of CD68 (h) in the nest of breast cancer with high expression of CD47 (g). 3,3'-Diaminobenzidine staining (brown), nuclear counterstaining (haematoxylin) 

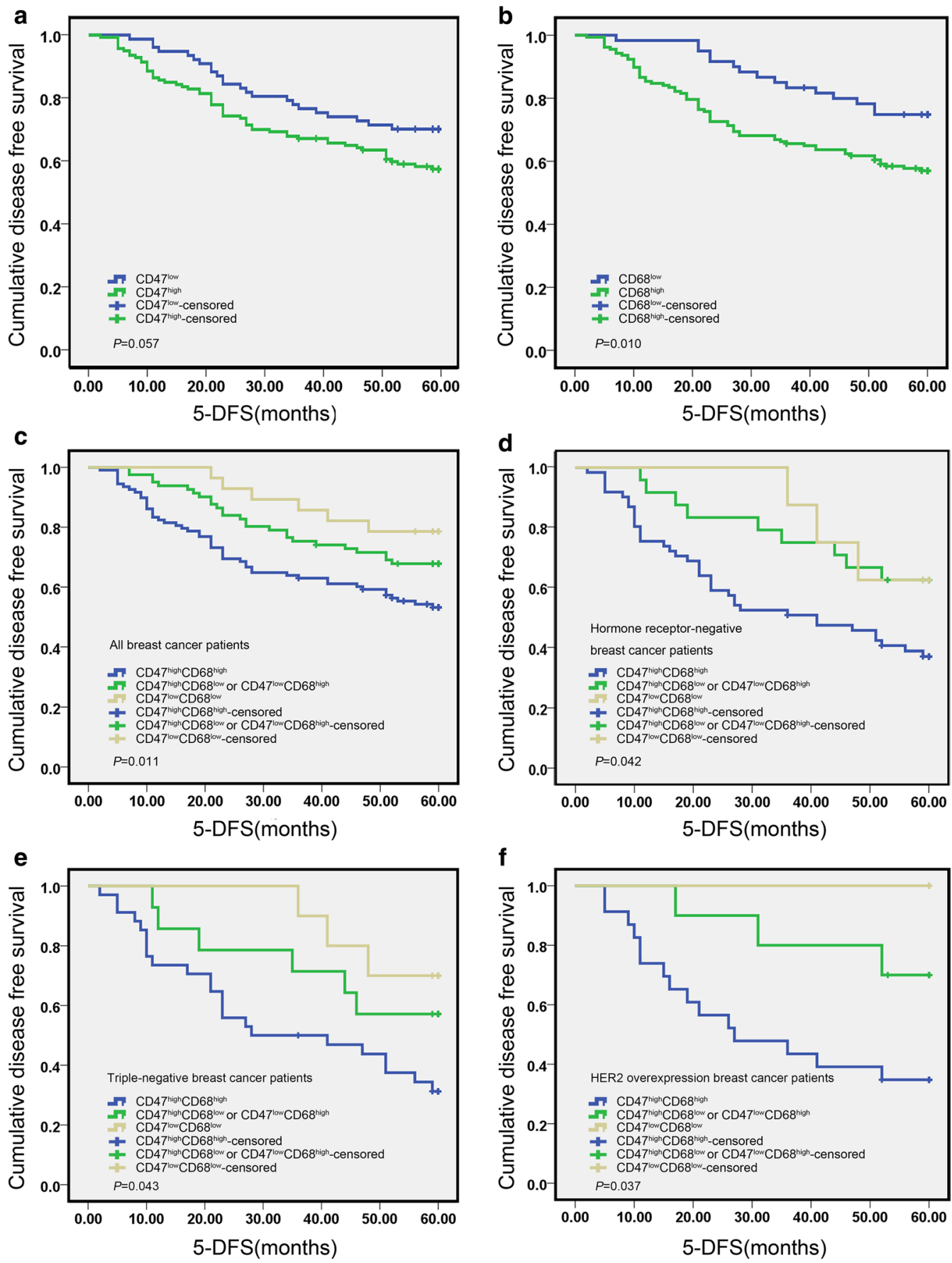

Fig. 2 Kaplan-Meier survival analysis showing the correlation between CD47 expression (a), CD68 expression (b), or CD47-CD68 expression (c) and 5-DFS in breast cancer patients (log-rank test). D-F, Kaplan-Meier survival analysis showing the correlation between CD47-CD68 expression and 5-DFS in hormone receptor-negative breast cancer (d), TNBC (e), and HER2 overexpression breast cancer patients (f) (log-rank test)

of CD68-labeled TAMs around or in the nest of breast cancer with high expression of CD47 (Fig. 1e-h). Subsequent analysis of the association between CD47 and CD68 expression showed that the expression of CD68 was positively correlated with that of CD47 $(\gamma=0.144, P=0.033)$.
In addition, combined high expression of CD47 and CD68 $\left(\mathrm{CD} 47^{\text {high }} \mathrm{CD} 68^{\text {high }}\right)$ were found in $49.8 \%$ of breast cancer patients $(108 / 217)$. What's more, $C D 47^{\text {high }} \mathrm{CD} 68^{\text {high }}$ had a significant association with advanced TNM stage $\left(X^{2}=16.769, P<0.001\right)$, histological grade $\left(x^{2}=11.300\right.$, 
Table 2 Multivariate analysis of prognostic variables including classical prognostic factors and CD47 for disease-free survival in breast cancer patients

\begin{tabular}{|c|c|c|c|c|}
\hline \multirow[t]{2}{*}{ Variables } & \multirow[t]{2}{*}{ Hazard ratio } & \multicolumn{2}{|l|}{$95 \% \mathrm{Cl}$} & \multirow[t]{2}{*}{$P$} \\
\hline & & Lower & Upper & \\
\hline TNM stage (II+ | vs. III) & 1.852 & 1.116 & 3.075 & 0.017 \\
\hline Histological grade (grade $1+2$ vs. grade 3 ) & 3.661 & 2.250 & 5.958 & $<0.001$ \\
\hline Lymph node metastasis (no vs. yes) & 2.769 & 1.402 & 5.472 & 0.003 \\
\hline ER status (negative vs. positive) & 0.675 & 0.369 & 1.236 & 0.203 \\
\hline PR status (negative vs. positive) & 1.133 & 0.649 & 1.978 & 0.661 \\
\hline HER2 gene (non-amplification vs. amplification) & 1.812 & 1.120 & 2.932 & 0.015 \\
\hline CD47 (low expression vs. high expression) & 1.732 & 0.970 & 3.093 & 0.063 \\
\hline
\end{tabular}

Significant $P$-values are shown in italic type

Table 3 Multivariate analysis of prognostic variables including classical prognostic factors and CD68 for disease-free survival in breast cancer patients

\begin{tabular}{|c|c|c|c|c|}
\hline \multirow[t]{2}{*}{ Variables } & \multirow[t]{2}{*}{ Hazard ratio } & \multicolumn{2}{|l|}{$95 \% \mathrm{Cl}$} & \multirow[t]{2}{*}{$P$} \\
\hline & & Lower & Upper & \\
\hline TNM stage (II + I vs. III) & 1.806 & 1.086 & 3.004 & 0.023 \\
\hline Histological grade (grade $1+2$ vs. grade 3 ) & 3.487 & 2.158 & 5.636 & $<0.001$ \\
\hline Lymph node metastasis (no vs. yes) & 2.867 & 1.455 & 5.648 & 0.002 \\
\hline ER status (negative vs. positive) & 0.627 & 0.351 & 1.120 & 0.115 \\
\hline PR status (negative vs. positive) & 1.236 & 0.713 & 2.143 & 0.450 \\
\hline HER2 gene (non-amplification vs. amplification) & 1.865 & 1.148 & 3.029 & 0.012 \\
\hline CD68 (low expression vs. high expression) & 1.507 & 0.791 & 2.873 & 0.212 \\
\hline
\end{tabular}

Significant $P$-values are shown in italic type

$P=0.004), \quad$ LNM $\quad\left(\chi^{2}=5.759, \quad P=0.016\right), \quad$ ER status $\left(\chi^{2}=8.253, P=0.004\right), P R$ status $\left(\chi^{2}=3.948, P=0.047\right)$ and recurrence $\left(\chi^{2}=10.507, P=0.001\right)$. Strikingly, patients with $\mathrm{CD} 47^{\text {high }} \mathrm{CD} 68^{\text {high }}$ displayed a poorer 5 -DFS and a worse clinical outcome compared to patients with both low expression of CD47 and CD68 (CD47 $\left.{ }^{\text {low }} \mathrm{CD} 68^{\text {low }}\right)$, or only one protein high expression $\left(\mathrm{CD} 47^{\text {high }} \mathrm{CD} 68^{\text {low }}\right.$ or $\mathrm{CD} 47^{\text {low }} \mathrm{CD} 68^{\text {high }}$ ) (Fig. 2c, $P=0.011$ ). Additionally, $\mathrm{CD} 47^{\text {high }} \mathrm{CD} 68^{\text {high }}$ served as a novel independent prognostic factor for poor DFS in breast cancer patients as revealed by multivariate analysis subjected to Cox proportional hazards model analysis (Table $4, P=0.045 ; \mathrm{HR}=1.714$, 95\% CI 1.012-2.905). These data suggested that the prognostic value of combined high expression of CD47 and CD68 is better than that of CD47 or CD68 alone.

Combined high expression of CD47 and CD68 is associated with the prognosis of hormone receptor-negative breast cancer

From Table 1, both of the expression of CD47 and CD68 are significantly correlated with ER and PR status, but not with HER2 gene, suggesting that high expression of
CD47 or CD68 may be related to hormone receptors. We also found that CD47 and CD68 expression were more abundant in hormone receptor-negative breast cancer, such as triple-negative breast cancer (TNBC) (Fig. 3a, b) and HER2 overexpression breast cancer (Fig. 3c, d), while the expression density of CD47 and CD68 decreased in luminal-type breast cancer (Fig. 3e, f). Similarly, the incidence of $\mathrm{CD} 47^{\text {high }} \mathrm{CD} 68^{\text {high }}$ in hormone receptor-negative breast cancer $(65.6 \%, 61 / 93)$ was significantly higher than that in luminal-type breast cancer $(37.9 \%, 47 / 124)$ $\left(x^{2}=16.297, P<0.001\right)$. From Table $5, C D 47^{\text {high }} C D 68^{\text {high }}$ had a significant association with advanced TNM stage $\left(X^{2}=14.997, P=0.001\right)$, histological grade $\left(X^{2}=11.714\right.$, $P=0.003), \operatorname{LNM}\left(\chi^{2}=6.094, P=0.014\right)$ and recurrence $\left(X^{2}=5.191, P=0.023\right)$ in hormone receptor-negative breast cancer patients. Kaplan-Mayer analysis and logrank test showed that $\mathrm{CD} 47^{\text {high }} \mathrm{CD} 68^{\text {high }}$ was associated with reduced 5-DFS $(P=0.042)$ in hormone receptornegative breast cancer patients (Fig. 2d). Moreover, CD $47^{\text {high }} \mathrm{CD} 68^{\text {high }}$ was also found to relate to poor 5-DFS in TNBC $(P=0.043)$ and HER2 overexpression breast cancer patients $(P=0.037)$ respectively (Fig. 2e, f). 
Table 4 Multivariate analysis of prognostic variables including classical prognostic factors and CD47-CD68 for diseasefree survival in breast cancer patients

\begin{tabular}{lllrr}
\hline Variables & Hazard ratio & 95\% Cl & U \\
\cline { 3 - 4 } & & Lower & Upper \\
\hline TNM stage (II + I vs. III) & & 1.086 & 2.999 & 0.023 \\
Histological grade (grade 1+2 vs. grade 3) & 3.368 & 2.069 & 5.484 & 0.001 \\
Lymph node metastasis (no vs. yes) & 2.779 & 1.408 & 5.485 & 0.003 \\
ER status (negative vs. positive) & 0.695 & 0.378 & 1.277 & 0.241 \\
PR status (negative vs. positive) & 1.218 & 0.697 & 2.128 & 0.489 \\
HER2 gene (non-amplification vs. amplification) & 1.825 & 1.127 & 2.955 & 0.014 \\
CD47-CD68 (both negative + one positive vs. both positive) & 1.714 & 1.012 & 2.905 & 0.045 \\
\hline
\end{tabular}

Significant $P$-values are shown in italic type

Additionally, cox proportional hazards model analysis indicated $\mathrm{CD} 47^{\text {high }} \mathrm{CD} 68^{\text {high }}$ was an independent predictor of poor DFS in hormone receptor-negative breast cancer patients (Table 6, $P=0.045 ; \mathrm{HR}=2.792$, 95\% CI 1.022-7.626). In summary, combined high expression of CD47 and CD68 is associated with the prognosis of breast cancer, especially for hormone receptor-negative breast cancer.

\section{Discussion}

CD47 has been considered as a biomarker of several carcinomas, and its high expression is also a poor clinical prognostic factor. However, the exact role of CD47 in the prognosis of breast cancer remains unclear. Manna et al. detected CD47 in breast cancer cell lines, and found that anti-CD47 monoclonal antibody 1F7 could induce the death of four different breast cancer cell lines (MCF7, HBL-100, MDA-MB-231, and AU-565) [28]. Nagahara et al. found higher expression of CD47 in the bone marrow and peripheral blood of breast cancer patients, moreover, they suggested that CD47 was an important biomarker in breast cancer and functioned as a prognostic factor for DFS [22]. Baccelli et al. showed that MET and CD47 were co-expressed in circulating tumor cells of breast cancer, and the co-expression of MET-CD47 was an independent prognostic factor for survival of luminal-type breast cancer patients [17, 25]. Zhang et al. [29] and Kaur et al. [27] reported that the increase of CD47 in breast cancer stem cells promoted evasion of phagocytosis.

Although these studies suggested that CD47 was overexpressed in breast cancer and associated with the development or prognosis of breast cancer, most studies are based on the detection of CD47 expression at the cytological level, there is little direct evidence to report the expression of CD47 in breast cancer solid tumors and its relationship with prognosis. In this study, 217 cases of primary invasive breast cancer tissues were collected to detect the expression of CD47, and we revealed the direct evidence that $\mathrm{CD} 47$ was overexpressed in breast cancer solid tumors. Moreover, high CD47 expression was associated with several clinicopathological parameters including TNM stage, histological grade, ER status, PR status and recurrence. However, high CD47 expression was not an independent and significant prognostic factor for DFS in a multivariate analysis. These results suggest that CD47 may be involved in the progression of breast cancer, but it has a limited prognostic role.

In the microenvironment of tumor inflammation, TAMs infiltrate into tumor masses and suppress the anti-tumor functions of cytotoxic $\mathrm{T}$ cells by secreting anti-inflammatory cytokines, they also recruit immunosuppressive leukocytes to the tumor microenvironment [7]. Accumulative evidence suggests that high TAMs density in tumors influences the overall progress of breast cancer and correlates with poor prognosis [7]. Bingle et al. reported that the increase of macrophage density in more than $80 \%$ of breast cancer patients was associated with poor prognosis, and patients with higher TAMs density had a significantly worse recurrence-free survival (RFS) and overall survival (OS) [30]. The relationship between the high infiltration rate of TAMs and the signs for poor prognosis such as high grade of tumors, low ER or PR receptor status, and high mitotic activity of tumors has also been reported [31]. In this study, CD68-labeled TAMs was significantly increased in breast cancer, and high macrophage infiltration was associated with advanced TNM stage, histological grade, LNM, ER status, PR status and recurrence. Further survival analysis showed a correlation between high expression of CD68 and reduced 5-DFS, but a limited prognostic value of CD68 expression was observed based on the multivariate Cox proportional analysis. 

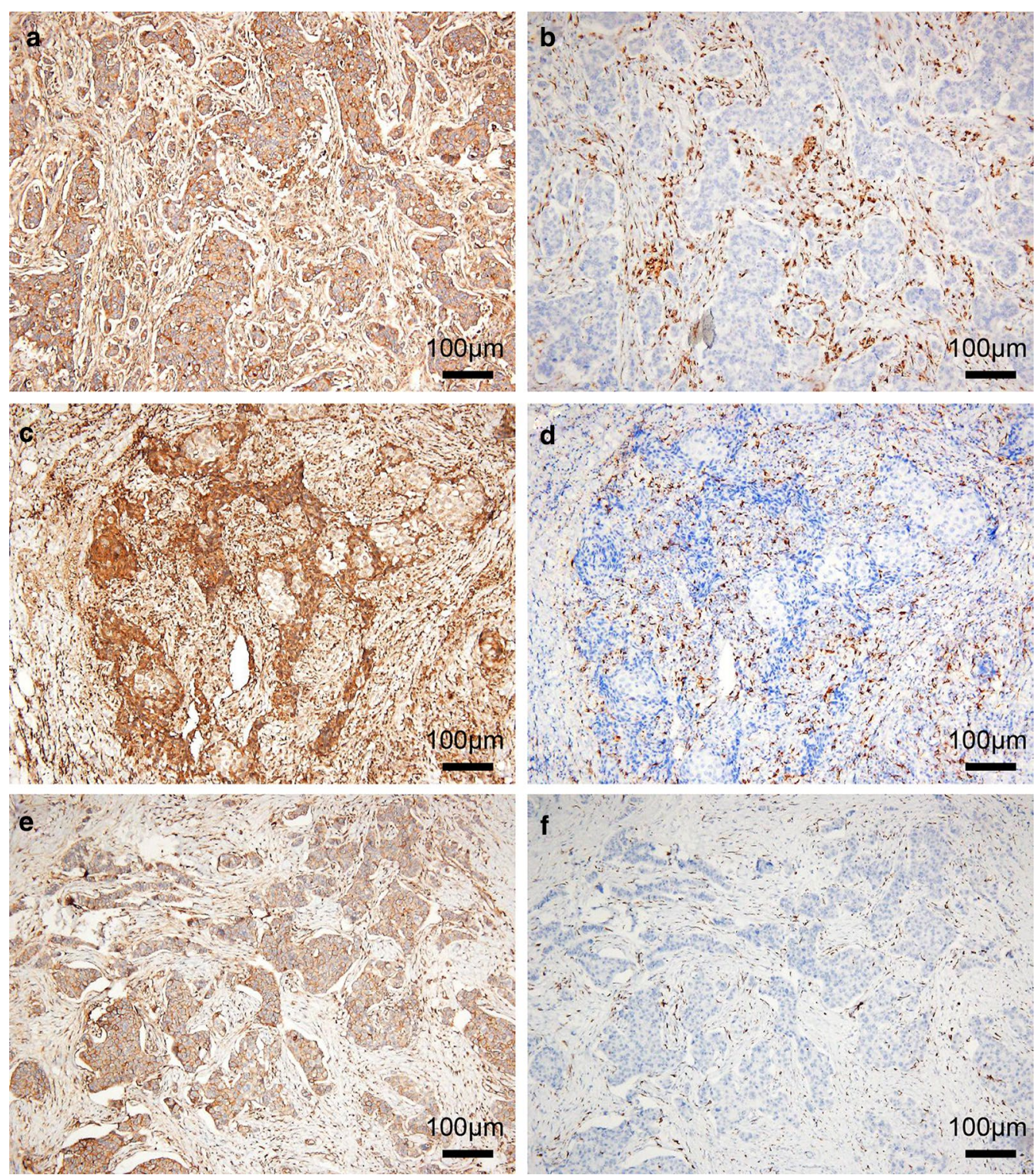

Fig. 3 Immunohistochemical staining for CD47 and CD68 in breast cancer with different molecular subtypes. A and B, The expression of CD47 (a) and CD68 (b) in TNBC. $\mathbf{c}$, d The expression of CD47 (c) and CD68 (d) in HER2 overexpression breast cancer. e, f The expression of CD47 (e) and CD68 (f) in luminal-type breast cancer. 3,3'-Diaminobenzidine staining (brown), nuclear counterstaining (haematoxylin)

Although the high expression of CD47 or CD68 had a limited prognostic role value according to the multivariate Cox proportional analysis, our study showed for the first time that combined high expression of CD47 and CD68 represented an even better independent predictor for poor DFS compared to the expression of CD47 or CD68 alone. Why did the patients with $\mathrm{CD} 47^{\text {high }} \mathrm{CD} 68^{\text {high }}$ displayed a more significant prognostic effect on the prognosis? We hypothesized that this may be related to immune escape. Since CD47 on the surface of tumor cells binds to the receptor SIRP- $\alpha$ on the macrophages to inhibit normal phagocytosis [12], the anti-phagocytosis effect based on CD47/ SIRP- $\alpha$ may be enhanced when CD47 expression is upregulated and macrophage density is increased, thus affecting the prognosis of breast cancer. Another question is why macrophage aggregation is more frequent in cancer tissues with high CD47 expression? In this study, the expression of CD68 was positively correlated with that of $\mathrm{CD} 47$, and $\mathrm{CD} 47^{\text {high }} \mathrm{CD} 68^{\text {high }}$ was found in $49.8 \%$ of breast cancer patients. Koelzer et al. reported that the prognostic impact of $\mathrm{CD}^{+} 8^{+}$infiltrates is 


\begin{tabular}{|c|c|c|c|c|}
\hline $\begin{array}{l}\text { Clinicopathological } \\
\text { factors }\end{array}$ & $\mathrm{n}$ & $\begin{array}{l}\text { CD47 } \\
\text { (\%) }\end{array}$ & $x^{2}$ & $P$ \\
\hline \multicolumn{5}{|l|}{ Age (years) } \\
\hline$<50$ & 54 & 64.81 & \multirow[t]{2}{*}{0.034} & \multirow[t]{2}{*}{0.853} \\
\hline$>50$ & 39 & 66.67 & & \\
\hline \multicolumn{5}{|l|}{ Menopause } \\
\hline Before & 44 & 61.36 & \multirow[t]{2}{*}{0.661} & \multirow[t]{2}{*}{0.416} \\
\hline After & 49 & 69.39 & & \\
\hline \multicolumn{5}{|l|}{ TNM stage } \\
\hline I & 3 & 33.33 & \multirow[t]{3}{*}{14.997} & \multirow[t]{3}{*}{0.001} \\
\hline$\|$ & 57 & 52.63 & & \\
\hline III & 33 & 90.91 & & \\
\hline \multicolumn{5}{|l|}{ Histological grade } \\
\hline G1 & 7 & 85.71 & \multirow[t]{3}{*}{11.714} & \multirow[t]{3}{*}{0.003} \\
\hline G2 & 47 & 48.94 & & \\
\hline G3 & 39 & 82.05 & & \\
\hline \multicolumn{5}{|c|}{ Lymph node metastasis } \\
\hline Yes & 54 & 75.93 & \multirow[t]{2}{*}{6.094} & \multirow[t]{2}{*}{0.014} \\
\hline No & 39 & 51.28 & & \\
\hline \multicolumn{5}{|l|}{ Recurrence } \\
\hline Yes & 50 & 76.00 & \multirow[t]{2}{*}{5.191} & \multirow[t]{2}{*}{0.023} \\
\hline No & 43 & 53.49 & & \\
\hline
\end{tabular}

Significant $P$-values are shown in italic type

strongly modified by the expression of the anti-phagocytic molecule CD47 on colorectal tumors [32]. On the other hand, aggregation of macrophages also affects the expression of CD47. Tumor immunosurveillance is a well-established mechanism of tumor growth regulation [33]. Inflammatory environments have been shown to promote the growth of tumors and some unique antigens on the surface of cancer cells could also induce inflammation [34]. In the inflammatory environments, many types of immune cells, including TAMs, infiltrate into tumor masses. Under this strong selective pressure, tumors need to up-regulate the expression of CD47 to avoid immunosurveillance [33].
Our study also confirmed the first time that the prognostic significance of combined high expression of CD47 and CD68 not only in breast cancer in general, but also in hormone receptor-negative breast cancer in particular. Patients with luminal-type breast cancer generally have a good prognosis with a 5 -year relative survival between 75 and $86 \%$ [35]. However, hormone receptor-negative breast cancer, including TNBC and HER2 overexpression breast cancer, usually has a poor prognosis. It is worth noting that the prognosis of TNBC is worse due to the lack of targeted therapy. We found that $\mathrm{CD} 47^{\text {high }} \mathrm{CD} 68^{\text {high }}$ was more abundant in hormone receptor-negative breast cancer compared with that in luminal-type breast cancer. Moreover, $\mathrm{CD} 47^{\text {high }} \mathrm{CD} 68^{\text {high }}$ was more significantly associated with the prognosis of hormone receptor-negative breast cancer in particular. Why does $\mathrm{CD} 47^{\text {high }} \mathrm{CD} 68^{\text {high }}$ have a higher prognostic value in hormone receptornegative breast cancer in particular? Historically, breast cancer has not been considered as a typical immunogenic tumor, however, it is well known that this disease is a highly heterogeneous disease [36]. The heterogeneity is reflected in the fact that although the less aggressive breast cancer does not exhibit high immune cell infiltration, it is highly immunogenic for breast cancer lacking hormone receptors [36]. A possible explanation is that TNBC and HER-2 overexpression breast cancer are highly proliferative types of tumors, and the genetic instability of these types of breast cancer causes the exposure of a large number of tumor antigens and promotes the anti-tumor immune response [36, 37]. Under this immune selective pressure, tumor cells need to upregulate the expression of CD47 and bind to the receptor SIRP- $\alpha$ on phagocytes to inhibit normal phagocytosis and promote immune escape [33], which may be one of the reasons for the high expression of CD47 and CD68 in hormone receptor-negative breast cancer.

It should be acknowledged that there are also some limitations in this study. Firstly, inflammatory environments have been shown to up-regulate the expression of CD47 to avoid immunosurveillance [33]. Studies also showed that microRNAs (such as miR-34a, miR-155, miR-326, miR-141, and miR-133a) and EMT-induced transcription

Table 6 Multivariate analysis of prognostic variables including classical prognostic factors and CD47-CD68 for diseasefree survival in hormone receptor-negative breast cancer

\begin{tabular}{|c|c|c|c|c|}
\hline \multirow[t]{2}{*}{ Variables } & \multirow[t]{2}{*}{ Hazard ratio } & \multicolumn{2}{|l|}{$95 \% \mathrm{Cl}$} & \multirow[t]{2}{*}{$P$} \\
\hline & & Lower & Upper & \\
\hline TNM stage (II + | vs. III) & 1.357 & 0.681 & 2.702 & 0.385 \\
\hline Histological grade (grade $1+2$ vs. grade 3 ) & 1.839 & 0.969 & 3.489 & 0.062 \\
\hline Lymph node metastasis (no vs. yes) & 2.640 & 1.096 & 6.356 & 0.030 \\
\hline CD47-CD68 (both negative + one positive vs. both positive) & 2.792 & 1.022 & 7.626 & 0.045 \\
\hline
\end{tabular}

Significant $P$-values are shown in italic type 
factors (such as SNAI1 or ZEB1) contribute to CD47 regulation [38-41]. However, the exact mechanism of CD47 overexpression in breast cancer solid tumors still unclear, which needs to be evaluated in the future study. Secondly, the prognostic significance of CD47 and CD68 in breast cancer was discussed only at histological level. The exact role of CD47 and CD68 in breast cancer, especially in hormone receptor-negative breast cancer, still needs to be evaluated in follow-up mechanistic investigations. Thirdly, a variety of growth factors and proliferating factors, such as epidermal growth factor (EGF), transforming growth factor (TGF), fibroblast growth factor (FGF), proliferating cell nuclear antigen (PCNA), Ki67, and Cyclin D1, are strongly involved in cell proliferation, differentiation, invasion and migration, thus regulating the prognosis of cancer. Therefore, exploring the relationship between CD47/CD68 protein and proliferation/ growth factor is also essential to better demonstrate the role of CD47 and CD68 in the prognosis of breast cancer. Fourthly, this study assessed prognosis through 5-DFS rather than OS. Since DFS is sometimes not linearly related to OS, the influence of CD47 and CD68 expression on OS is still a topic for future research.

\section{Conclusion}

Our study showed for the first time that $\mathrm{CD} 47^{\text {high }} \mathrm{CD} 68^{\text {high }}$ represented an even better independent predictor for poor prognosis compared to the expression of CD47 or CD68 alone in breast cancer patients, especially in patients lacking of hormone receptor.

\section{Acknowledgements}

Not applicable.

\section{Authors' contributions}

$J Y$ and HY made contributions to the conception and design of the study; CC and JW collected the samples and performed immunohistochemistry experiments; JR made contributions to statistical analysis; JY and HH evaluated the immunohistochemical staining of all sections; $\mathrm{HY}$ made contributions to critical revision of the manuscript. All authors read and approved the final manuscript.

\section{Funding}

This work was supported by grants from National Natural Science Foundation of China (Grant No. 31600866), Science and Technology Planning Project of Wuhan (Grant No. 2017060201010172) and Guidance Foundation of Renmin Hospital of Wuhan University (Grant No. RMYD2018M27).

\section{Availability of data and materials}

Not applicable.

\section{Ethics approval and consent to participate}

This study was approved by the Ethical Committee of Renmin Hospital of Wuhan University (WDRY2019-K010). The written informed consents were obtained from all the patients.

\section{Consent for publication}

Not applicable.

\section{Competing interests}

The authors declare that they have no competing interests.

\section{Author details}

${ }^{1}$ Department of Pathology, Renmin Hospital of Wuhan University, No.99, Zhangzhidong Road, Wuchang District, Wuhan 430060, Hubei, People's Republic of China. ${ }^{2}$ Department of Breast and Thyroid Surgery, Renmin Hospital of Wuhan University, Wuhan 430060, Hubei, People's Republic of China.

Received: 21 May 2019 Accepted: 3 September 2019

Published online: 11 September 2019

\section{References}

1. Harbeck N, Gnant M. Breast cancer. Lancet. 2017;389:1134-50.

2. Fan L, Strasser-Weippl K, Li JJ, et al. Breast cancer in China. Lancet Oncol. 2014;15:e279-89.

3. Wu T, Dai Y. Tumor microenvironment and therapeutic response. Cancer Lett. 2017;387:61-8.

4. Katheder NS, Khezri R, O'Farrell F, et al. Microenvironmental autophagy promotes tumour growth. Nature. 2017;541:417-20.

5. Komohara Y, Jinushi M, Takeya M. Clinical significance of macrophage heterogeneity in human malignant tumors. Cancer Sci. 2014;105:1-8.

6. Zhao X, Qu J, Sun Y, et al. Prognostic significance of tumor-associated macrophages in breast cancer: a meta-analysis of the literature. Oncotarget. 2017;8:30576-86.

7. Choi J, Gyamfi J, Jang H, Koo JS. The role of tumor-associated macrophage in breast cancer biology. Histol Histopathol. 2018;33:133-45.

8. Tiainen S, Tumelius R, Rilla K, et al. High numbers of macrophages, especially M2-like (CD163-positive), correlate with hyaluronan accumulation and poor outcome in breast cancer. Histopathology. 2015;66:873-83.

9. Fan $\mathrm{QM}$, Jing $\mathrm{YY}, \mathrm{Yu} \mathrm{GF}$, et al. Tumor-associated macrophages promote cancer stem cell-like properties via transforming growth factor-beta1induced epithelial-mesenchymal transition in hepatocellular carcinoma. Cancer Lett. 2014:352:160-8.

10. Hollmen M, Roudnicky F, Karaman S, Detmar M. Characterization of macrophage-cancer cell crosstalk in estrogen receptor positive and triple-negative breast cancer. Sci Rep. 2015;5:9188.

11. Feng MY, Chen JY, Weissman-Tsukamoto R, et al. Macrophages eat cancer cells using their own calreticulin as a guide: roles of TLR and Btk. Proc Natl Acad Sci USA. 2015;112:2145-50.

12. Vonderheide RH. CD47 blockade as another immune checkpoint therapy for cancer. Nat Med. 2015;21:1122-3.

13. Zhang $\mathrm{L}$, Huang $\mathrm{H}$. Targeting the cancer biomarker $\mathrm{CD} 47$ : a review on the diverse mechanisms of the CD47 pathway in cancer treatment. Anticancer Agents Med Chem. 2016;16:658-67.

14. Chao MP, Alizadeh AA, Tang C, et al. Anti-CD47 antibody synergizes with rituximab to promote phagocytosis and eradicate non-Hodgkin lymphoma. Cell. 2010;142:699-713.

15. Chao MP, Alizadeh AA, Tang C, et al. Therapeutic antibody targeting of CD47 eliminates human acute lymphoblastic leukemia. Can Res. 2011:71:1374-84.

16. Chan KS, Espinosa I, Chao M, et al. Identification, molecular characterization, clinical prognosis, and therapeutic targeting of human bladder tumor-initiating cells. Proc Natl Acad Sci USA. 2009;106:14016-21.

17. Baccelli I, Stenzinger A, Vogel V, et al. Co-expression of MET and CD47 is a novel prognosticator for survival of luminal-type breast cancer patients. Oncotarget. 2014;5:8147-60.

18. Kim D, Wang J, Willingham SB, et al. Anti-CD47 antibodies promote phagocytosis and inhibit the growth of human myeloma cells. Leukemia. 2012:26:2538-45.

19. Xiao Z, Chung H, Banan B, et al. Antibody mediated therapy targeting CD47 inhibits tumor progression of hepatocellular carcinoma. Cancer Lett. 2015;360:302-9.

20. Casey SC, Tong L, Li YL, et al. MYC regulates the antitumor immune response through CD47 and PD-L1. Science. 2016;352:227-31.

21. McCracken MN, Cha AC, Weissman IL. Molecular pathways: activating T cells after cancer cell phagocytosis from blockade of CD47 "Don't Eat Me" signals. Clin Cancer Res. 2015;21:3597-601.

22. Nagahara M, Mimori K, Kataoka A, et al. Correlated expression of CD47 and SIRPA in bone marrow and in peripheral blood predicts recurrence in breast cancer patients. Clin Cancer Res. 2010;16:4625-35. 
23. Willingham SB, Volkmer JP, Gentles AJ, et al. The CD47-signal regulatory protein alpha (SIRPa) interaction is a therapeutic target for human solid tumors. Proc Natl Acad Sci USA. 2012;109:6662-7.

24. Yoshida K, Tsujimoto H, Matsumura K, et al. CD47 is an adverse prognostic factor and a therapeutic target in gastric cancer. Cancer Med. 2015;4:1322-33.

25. Baccelli I, Schneeweiss A, Riethdorf S, et al. Identification of a population of blood circulating tumor cells from breast cancer patients that initiates metastasis in a xenograft assay. Nat Biotechnol. 2013:31:539-44.

26. Bener G, Felix AJ, Sanchez de Diego C, et al. Silencing of CD47 and SIRPalpha by polypurine reverse Hoogsteen hairpins to promote MCF-7 breast cancer cells death by PMA-differentiated THP-1 cells. BMC Immunol. 2016;17:32.

27. Kaur S, Elkahloun AG, Singh SP, et al. A function-blocking CD47 antibody suppresses stem cell and EGF signaling in triple-negative breast cancer. Oncotarget. 2016;7:10133-52.

28. Manna PP, Frazier WA. CD47 mediates killing of breast tumor cells via Gidependent inhibition of protein kinase A. Cancer Res. 2004;64:1026-36.

29. Zhang $H$, Lu H, Xiang L, et al. HIF-1 regulates CD47 expression in breast cancer cells to promote evasion of phagocytosis and maintenance of cancer stem cells. Proc Natl Acad Sci USA. 2015;112:E6215-23.

30. Bingle $\mathrm{L}$, Brown NJ, Lewis CE. The role of tumour-associated macrophages in tumour progression: implications for new anticancer therapies. J Pathol. 2002;196:254-65.

31. Volodko N, Reiner A, Rudas M, Jakesz R. Tumour-associated macrophages in breast cancer and their prognostic correlations. Breast. 1998;7:99-105

32. Koelzer VH, Canonica K, Dawson H, et al. Phenotyping of tumor-associated macrophages in colorectal cancer: impact on single cell invasion (tumor budding) and clinicopathological outcome. Oncoimmunology. 2016;5:e1106677.
33. Jaiswal S, Chao MP, Majeti R, Weissman IL. Macrophages as mediators of tumor immunosurveillance. Trends Immunol. 2010;31:212-9.

34. Tlsty TD, Coussens LM. Tumor stroma and regulation of cancer development. Annu Rev Pathol. 2006;1:119-50.

35. Zaha DC, Lazar E, Lazureanu C. Clinicopathologic features and five years survival analysis in molecular subtypes of breast cancer. Rom J Morphol Embryol. 2010;51:85-9.

36. Denkert $C$. The immunogenicity of breast cancer-molecular subtypes matter. Ann Oncol. 2014;25:1453-5.

37. Gajewski TF, Schreiber H, Fu YX. Innate and adaptive immune cells in the tumor microenvironment. Nat Immunol. 2013;14:1014-22.

38. Junker A, Krumbholz M, Eisele S, et al. MicroRNA profiling of multiple sclerosis lesions identifies modulators of the regulatory protein CD47. Brain. 2009:132:3342-52.

39. Tang W, Qin J, Tang J, et al. Aberrant reduction of MiR-141 increased CD47/CUL3 in Hirschsprung's disease. Cell Physiol Biochem. 2013;32:1655-67.

40. Suzuki S, Yokobori T, Tanaka N, et al. CD47 expression regulated by the miR-133a tumor suppressor is a novel prognostic marker in esophageal squamous cell carcinoma. Oncol Rep. 2012;28:465-72.

41. Noman MZ, Van Moer K, Marani V, et al. CD47 is a direct target of SNAl1 and ZEB1 and its blockade activates the phagocytosis of breast cancer cells undergoing EMT. Oncoimmunology. 2018;7:e1345415.

\section{Publisher's Note}

Springer Nature remains neutral with regard to jurisdictional claims in published maps and institutional affiliations.
Ready to submit your research? Choose BMC and benefit from:

- fast, convenient online submission

- thorough peer review by experienced researchers in your field

- rapid publication on acceptance

- support for research data, including large and complex data types

- gold Open Access which fosters wider collaboration and increased citations

- maximum visibility for your research: over $100 \mathrm{M}$ website views per year

At BMC, research is always in progress.

Learn more biomedcentral.com/submissions 